\title{
The Timing of Mortality Decline and Human Capital Accumulation
}

\author{
Yusuke Hirota \\ Osaka City University, Sumiyoshi, Japan \\ Email: hiroty@econ.osaka-cu.ac.jp
}

Received 9 December 2015; accepted 16 December 2015; published 3 February 2016

Copyright (C) 2016 by author and Scientific Research Publishing Inc.

This work is licensed under the Creative Commons Attribution International License (CC BY). http://creativecommons.org/licenses/by/4.0/

c) (i) Open Access

\begin{abstract}
In this paper, we rigorously reinvestigate the effects of childhood mortality decline during different periods on human capital accumulation and economic development. For this purpose, we extend the basic framework of Azarnert (2006) by dividing childhood among three periods-early childhood (the period prior to school enrolment), school age (the school-enrolment period), and late childhood (the period posterior to school enrolment)-and assume a constant mortality rate for each period. We arrive at the following conclusions. The mortality decline after school age promotes human capital accumulation and economic development. The mortality decline after early childhood impedes human capital accumulation and economic development, but has no effect on the same after late childhood.
\end{abstract}

\section{Keywords}

Human Capital Accumulation, Timing of Mortality Decline, Economic Development

\section{Introduction}

Many previous studies have analyzed the effects of a decline in the childhood mortality rate on human capital accumulation. Kalemli-Ozcan [1] [2] found that a mortality decline promotes human capital accumulation under uncertainty. Kalemli-Ozcan [2] studied the mortality rate among the below-school-enrolment age population, whereas Kalemli-Ozcan [1] investigated the impact of the mortality rate among the population that was just about to start work (after school enrolment). Kalemli-Ozcan [1] considered that individuals simultaneously decide about educational investment and fertility. By contrast, Kalemli-Ozcan [2] assumed that individuals take decisions about educational investment after deciding about fertility. In contrast, Azarnert [3] did not use a model under uncertainty and expanded a previous model by adding an opportunity cost for the difference between the early childhood and school-age periods. He demonstrated that a decline in mortality rate among the 
age group prior to school enrolment impeded human capital accumulation. He remarked that this finding opposes previous studies that considered a decline in mortality after educational investment. However, to date, no study has used a model under uncertainty to explore whether mortality decline after education promotes human capital accumulation. ${ }^{1}$

Thus, previous studies, including Kalemli-Ozcan [1] [2] and Azarnert [3], did not rigorously compare the mortality declines prior and posterior to school enrolment. Notably, we should consider the fact that not only is the gap between the primary and secondary education enrolment rates higher but also the rate of completion of primary education is lower for low-income countries; the working period does not begin immediately after (primary) school education is completed. ${ }^{2}$ That is to say, we think that it is important to consider another period between completing (primary) school education and working, which has not been considered in previous studies. The mortality during this period is relatively low, but we nevertheless explore this point. ${ }^{3}$ Accordingly, we divide childhood into three periods: the period before school enrolment, the school-enrolment period, and the period after school enrolment. Using this kind of setting helps us to rigorously review the impacts of the decline in mortality during different times on human capital accumulation and economic development.

The reminder of this paper is organized as follows. Section 2 presents our model. In Section 3, we investigate how declines in respective mortality rates affect human capital accumulation and economic development. Section 4 concludes.

\section{Model}

We assume an economy with overlapping generations. In each generation, homogenous individuals live for three periods (childhood, adulthood, and old age), where childhood consists of three subperiods (early childhood, school age, and late childhood). ${ }^{4}$ There are three types of survival ratios, and when shifting between each subperiod - namely, from early childhood to school age, from school age to late childhood, and from late childhood to adulthood-a certain number of people die. The respective survival ratios are $p_{b}, p_{c}$, and $p_{d}$. Here, $0<p_{b}, p_{c}, p_{d} \leq 1$. According to the previous research, survival ratio $p_{b}$ corresponds to the mortality prior to school enrolment, and $p_{d}$, to the mortality posterior to school enrolment.

Human capital accumulation is an increasing function of the educational level, $e_{t}$, that parents can afford for their children. Human capital production function for individuals born in the period $t$ is assumed to be:

$$
h_{t+1}=\left(1+\gamma e_{t}\right)^{\delta},
$$

where $0<\delta<1$ and $\gamma>0 . e_{t}$ is the educational investment per child.

Individuals belonging to the $t$ generation are born at the start of period $t-1$. In childhood, only those of school age receive an education. In this case, it is assumed that children do not have the right make their own decisions regarding education. In adulthood, people give birth to $n_{t}$ children, raise them, get them educated, transfer income to their parents, and themselves become consumers. Individuals receive an income, $h_{t} w$, in return for their labor. Here, $h_{t}$ is the level of human capital generated by individuals in the $t$ generation, and $w$ is the labor wage rate. Within it, the $\alpha$ component, $\alpha h_{t} w$, is transferred to the parents. ${ }^{5}$ The remaining income is used to raise the children. The net cost of raising children is the amount remaining after subtracting the income earned through child labor from the gross costs of raising the children. These child-raising costs per child in the subperiods of early childhood, school age, and late childhood are represented as $z_{a} h_{t} w, z_{b} h_{t} w$, and $z_{c} h_{t} w$, respectively. In other words, the child-raising costs in each subperiod are $z_{a} n_{t} h_{t} w, z_{b} p_{b} n_{t} h_{t} w$, and $z_{c} p_{b} p_{c} n_{t} h_{t} w$. The remaining income, after subtracting the income transferred to the parents and the child-raising

\footnotetext{
${ }^{1}$ Strulik [4], Fioroni [5], and Nakamura [6] addressed the mortality rate among the pre-school-enrolment-age population (early childhood). Lagerlöf [7], Strulik [8], and Tamura [9] studied the mortality rate among the after-school-enrolment-age population (late childhood).

${ }^{2}$ These facts are based on the following indicators provided by the World Bank: "Primary completion rate, both sexes (\%)" and "Net enrolment rate, primary and secondary, both sexes (\%).” Source: http://data.worldbank.org/indicator/all (Accessed 10 January 2016).

${ }^{3}$ For example, there are cases where, in developing countries, girls within this age group are forced into marriage, become pregnant subsequently, and die owing to complications arising from underage pregnancies.

${ }^{4}$ Early childhood is from 0 to 4 - 5 years, school age is from 5 - 6 to 10 - 12 years, and late childhood is from 11 - 13 to 13 - 15 years.

${ }^{5}$ This assumes that there is the custom of transferring a certain fraction of income to the parents and distributing the remainder to oneself and the children. Zhang and Nishimura [10] showed that parents bear and rear children because they expect children to care for them in old age. Tamura [11] and Strulik [8] made the same assumption. Similarly, Ehrlich and Lui [12], Morand [13], and Chakraborty and Das [14] assumed that one part of the income earned by the children is transferred to their parents. Chen [15] also assumed that a certain fraction of income is transferred from the parents to the children.
} 
costs, is allocated to personal consumption, $c_{y t}$, and educational investment for the child. Educational investment per child, $e_{t}$, is undertaken for $p_{b} n_{t}$ surviving children. Finally, in old age, individuals receive income from $p_{b} p_{c} p_{d} n_{t}$ children who have survived to adulthood, and they consume $c_{o t+1}$. The utility is assumed to be obtained from consumption in adulthood and old age. From the above, the problem of the $t$-generation individuals can be described as follows:

$$
\begin{aligned}
\operatorname{cox}_{c_{t}, c_{o t+1}, e_{t}, n_{t}} U_{t} & \equiv \beta \ln c_{y t}+(1-\beta) \ln c_{o t+1}, \\
\text { s.t. } \quad c_{y t} & =\left[1-\alpha-\left(z_{a}+z_{b} p_{b}+z_{c} p_{b} p_{c}\right) n_{t}\right] h_{t} w-p_{b} n_{t} e_{t}, \\
c_{o t+1} & =\alpha h_{t+1} w p_{b} p_{c} p_{d} n_{t} .
\end{aligned}
$$

where $0<\alpha, \beta, z_{a}, z_{b}, z_{c}<1$ and $w>0$.

In this instance, the decision concerns whether to undertake educational investment, and if so, to estimate the level of investment within a range of positive values. Thus, as educational investment never takes a negative value, a non-negative constraint is imposed on it. Accordingly, the level of human capital accumulation for the decision $e_{t}=0$ falls within the following range:

$$
h_{t} \leq \frac{1}{\left(z_{a} \frac{1}{p_{b}}+z_{b}+z_{c} p_{c}\right) \delta \gamma w} \equiv \hat{h} .
$$

Thus, in the event the decision is made in favor of an educational investment, $h_{t}>\hat{h}$, the optimum value of the educational level is

$$
e_{t}=\frac{\delta}{1-\delta}\left(z_{a} \frac{1}{p_{b}}+z_{b}+z_{c} p_{c}\right) h_{t} w-\frac{1}{(1-\delta) \gamma} .
$$

When the ratio of the surviving children in the school-enrolment period, $p_{b}$, rises, educational attainment, $e_{t}$, decreases $\left(\partial e_{t} / \partial p_{b}<0\right)$, when the ratio of the population surviving after school enrolment, $p_{c}$ rises, $e_{t}$ increases $\left(\partial e_{t} / \partial p_{c}>0\right)$, and when the ratio of the population surviving into adulthood, $p_{d}$ rises, $e_{t}$ does not change $\left(\partial e_{t} / \partial p_{d}=0\right)$. To understand these results, we need to analyze the marginal costs of educational investment, $p_{b} n_{t}$ (the second term on the right-hand side of Equation (2b)). ${ }^{6}$ As obtaining education becomes more difficult when $p_{b} n_{t}$ becomes larger, individuals reduce their educational attainment. In contrast, as obtaining education becomes easier for individuals when $p_{b} n_{t}$ grows smaller, they increase their educational attainment. An increase in $p_{b}$ has two effects. The first is the direct effect from $p_{b}$ in the rising $p_{b} n_{t}$. The second effect is the indirect effect from when the number of births, $n_{t}$, in $p_{b} n_{t}$ rises. There are cases when a rise in $p_{b}$ causes $n_{t}$ to increase; while, there are also cases in which a rise in $p_{b}$ causes $n_{t}$ to decrease. ${ }^{7}$ However, even in cases where a rise in $p_{b}$ causes $n_{t}$ to decline, $p_{b} n_{t}$ will definitely increase from the direct effects of $p_{b}$; therefore, education will decrease as a result of an increase in $p_{b}$. Next, as a rise in $p_{c}$ entails only indirect effects, the level of educational attainment increases. Finally, as $p_{c}$ does not affect $p_{b} n_{t}$, the level of educational attainment remains unchanged.

Upon substituting Equation (4) into Equation (1), the human capital dynamic equation becomes as follows:

$$
h_{t+1}=\left(\frac{\delta}{1-\delta}\right)^{\delta}\left[\gamma\left(z_{a} \frac{1}{p_{b}}+z_{b}+z_{c} p_{c}\right) h_{t} w-1\right]^{\delta} \equiv \eta\left(h_{t}: p_{b}, p_{c}\right) .
$$

This equation is illustrated in Figure 1, which shows three steady-state equilibrium points; $h^{*}$ and 1 are the stable stationary equilibrium points, and $h^{* *}$ is the unstable stationary equilibrium point. Therefore, if the level

\footnotetext{
${ }^{6}$ Per unit educational investment costs are $p_{b} n_{t}=\frac{\gamma(1-\delta)(1-\beta)(1-\alpha) h_{t} w}{\gamma\left(z_{a} \frac{1}{p_{b}}+z_{b}+z_{c} p_{c}\right) h_{t} w-1}$.

${ }^{7}$ The condition is $\partial n_{t} / \partial p_{b} \gtreqless 0 \Leftrightarrow \gamma\left(z_{b}+z_{c} p_{c}\right) h_{t} w-1 \lesseqgtr 0$.
} 


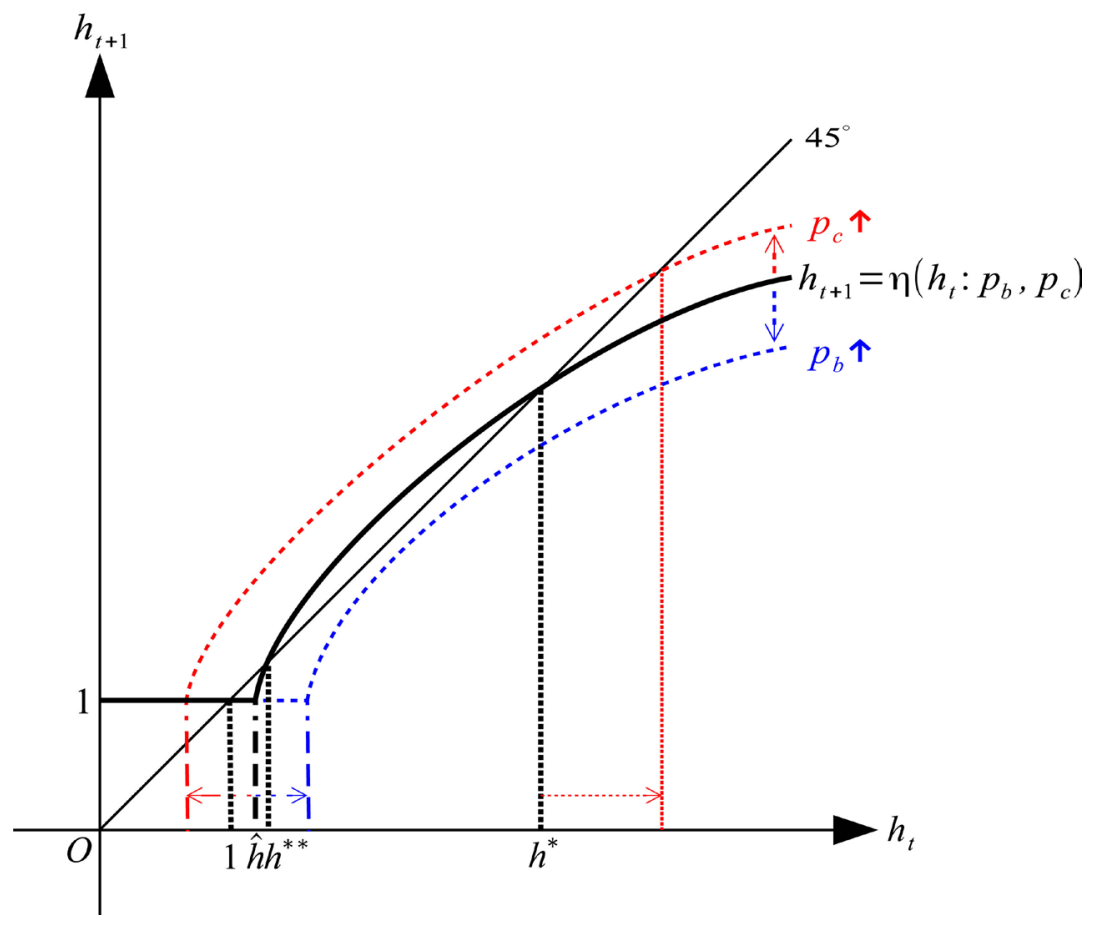

Figure 1. Phase diagram.

of the initial value $h_{0}$ is lower than $h^{* *}$, it converges on the lower steady-state equilibrium point, 1 (i.e., $h_{t}=1$ ), and if the level is higher, it converges on the high steady-state equilibrium point, $h^{*}$.

\section{The Effects of Childhood Mortality Decline on Human Capital Accumulation and Economic Development}

The effects of each survival ratio on human capital accumulation are the same as those on educational investment. When $p_{b}$ rises, human capital decreases $\left(\partial h_{t+1} / \partial p_{b}<0\right)$. When $p_{c}$ rises, human capital increases $\left(\partial h_{t+1} / \partial p_{c}>0\right)$. However, when $p_{d}$ increases, there is no effect on human capital $\left(\partial h_{t+1} / \partial p_{d}=0\right)$.

A rise in the survival ratio affects economic development. Therefore, we assume that the level of human capital accumulation is initially smaller than the threshold, $\hat{h}$, that is, individuals decide not to educate and the economy stagnates. The respective increases in the survival ratios will have the following effects. First, in Figure 1, when $p_{b}$ rises, the path traced by the dynamic equation will shift downwards (shown by the path traced by the blue dotted line). Because of this shift, $h^{* * *}$ shifts upwards, and the range of $h_{t}$, which can be directed to $h^{*}$, narrows. Further, this shift transforms the economy into one in which both $h^{* *}$ and $h^{*}$ eliminated and all $h_{t}$ converge at $1 .^{8}$ Moreover, when $p_{c}$ rises, the path traced by the dynamic equation shifts upwards (indicated by the path traced by the red dotted line). This shift pushes $h^{* *}$ downwards, and the range of $h_{t}$, as it starts moving toward $h^{*}$, becomes wider. Further, this shift transforms the economy into one where both $h^{* *}$ and 1 are eliminated, and all $h_{t}$ converge at $h^{*}{ }^{9}$ Finally, there is no effect even if $p_{d}$ rises.

Regarding an economy that is escaping stagnation and its destination on achieving continuous growth, the respective increases in the survival ratios will have the following effects. An increase in $p_{b}$ will push $h^{*}$ downwards and decrease human capital accumulation at its destination. An increase in $p_{c}$ will push $h^{*}$ upwards and increase human capital accumulation at its destination. However, there will be no effect even if $p_{d}$ rises.

\footnotetext{
${ }_{8}^{8}$ It becomes difficult to meet the non-negative constraint condition for the educational level (from Equation (3)). This is because as it moderates the slope of Equation (4), the range of $h_{t}$ that can take a negative value for the optimal value of the educational level becomes wider and the intention for education disappears.

${ }^{9}$ It becomes easier to satisfy the non-negative condition for the educational level. This is because the effect of the mortality rate is converse to that of an increase in $p_{b}$.
} 


\section{Conclusions}

In this study, we rigorously reinvestigate the impacts of different declines in the mortality rate on human capital accumulation and economic development, depending on the difference in the timing of childhood. Toward this end, we divide childhood into three periods_-early childhood (the period prior to school enrolment), school age (the school-enrolment period), and late childhood (the period posterior to school enrolment) —and assume a constant mortality rate for each period.

With these settings, we obtain the following main result. Among the three periods, the decline of the mortality after school age is important for human capital accumulation and economic development. This decline augments human capital accumulation and promotes economic development. In addition to this main result, we show that decreased mortality after early childhood reduces human capital accumulation and impedes economic development, while human capital accumulation and economic development are unaffected if mortality declines after late childhood. Of course, this paper suffers from some limitations. We need to include uncertainty into our model. Further, we should incorporate the cause of death, such as disease, in our model.

\section{Acknowledgements}

The author would like to thank Tetsuya Nakajima, the seminar participants of KMSG at Kwansei Gakuin University for their comments, and the referees for useful suggestions that helped her improve the original manuscript. This work was supported by JST/JICA, SATREPS.

\section{References}

[1] Kalemli-Ozcan, S. (2003) A Stochastic Model of Mortality, Fertility, and Human Capital Investment. Journal of Development Economics, 70, 103-118. http://dx.doi.org/10.1016/s0304-3878(02)00089-5

[2] Kalemli-Ozcan, S. (2008) The Uncertain Lifetime and the Timing of Human Capital Investment. Journal of Population Economics, 21, 557-572. http://dx.doi.org/10.1007/s00148-007-0145-8

[3] Azarnert, L. (2006) Child Mortality, Fertility, and Human Capital Accumulation. Journal of Population Economics, 19, 285-297. http://dx.doi.org/10.1007/s00148-005-0020-4

[4] Strulik, H. (2004) Child Mortality, Child Labour and Economic Development. Economic Journal, 114, 547-568. http://dx.doi.org/10.1111/j.1468-0297.2004.00231.x

[5] Fioroni, T. (2010) Child Mortality and Fertility: Public vs Private Education. Journal of Population Economics, 23, 73-97. http://dx.doi.org/10.1007/s00148-009-0248-5

[6] Nakamura, H. (2015) The Effects of Child Mortality Changes on Two Income Groups and Macroeconomics. KIER Working Papers, 920, 1-31. http://www.kier.kyoto-u.ac.jp/DP/DP920.pdf

[7] Lagerlöf, N. (2003) From Malthus to Modern Growth: Can Epidemics Explain the Three Regimes? International Economic Review, 44, 755-777. http://dx.doi.org/10.1111/1468-2354.t01-1-00088

[8] Strulik, H. (2003) Mortality, the Trade-Off between Child Quality and Quantity, and Demo-Economic Development. Metroeconomica, 54, 499-520. http://dx.doi.org/10.1111/1467-999X.00177

[9] Tamura, R. (2006) Human Capital and Economic Development. Journal of Development Economics, 79, $26-72$. http://dx.doi.org/10.1016/j.jdeveco.2004.12.003

[10] Zhang, J. and Nishimura, K. (1993) The Old-Age Security Hypothesis Revisited. Journal of Development Economics, 41, 191-202. http://dx.doi.org/10.1016/0304-3878(93)90047-Q

[11] Tamura, R. (2000) Growth, Fertility and Human Capital: A Survey. Spanish Economic Review, 2, 183-229. http://dx.doi.org/10.1007/PL00013579

[12] Ehrlich, I. and Lui, F.T. (1991) Intergenerational Trade, Longevity, and Economic Growth. Journal of Political Economy, 99, 1029-1059. http://dx.doi.org/10.1086/261788

[13] Morand, O.F. (1999) Endogenous Fertility, Income Distribution, and Growth. Journal of Economic Growth, 4, 331349. http://dx.doi.org/10.1023/A:1009884804855

[14] Chakraborty, S. and Das, M. (2005) Mortality, Fertility, and Child Labor. Economics Letters, 86, 273-278. http://dx.doi.org/10.1016/j.econlet.2004.06.021

[15] Chen, H. (2005) Educational Systems, Growth and Income Distribution: A Quantitative Study. Journal of Development Economics, 76, 325-353. http://dx.doi.org/10.1016/j.jdeveco.2003.12.016 